\title{
Arquivos urbanos: meio ambiente entre nomeações e imagens
}

\author{
Telma Domingues da Silval
}

\begin{abstract}
Résumé: Le présent article vise à contribuer à une meilleure compréhension de la densité de l'archive, dans son engagement avec la mémoire discursive. De divers matériaux ont été pris à l'analyse (récits, images, témoignages) qui se rapportent à la relation de la rivière avec la ville. La recherche m'a montré que l'enquête sur la mémoire de la rivière est un point d'intérêt pour effleurer le réel de la mémoire de la ville, en cherchant particulièrement les éléments significatifs d'un processus d'urbanisation, un rapport au soi-disant environnement, et la voie selon laquelle se reproduisent le sujets (urbains). La coupure des analyses montre une trajectoire théorique-analytique qui se profile dans le sens de comprendre des relations de passage entre des nominations et des images.
\end{abstract}

Mots-clé: mémoire discursive; discurse environnementel; sujets urbains; circulacion de l'archive.

Resumo: O presente artigo procura contribuir para uma compreensão da densidade do arquivo, no seu embate com a memória discursiva. Foram tomados para análise materiais diversos (narrativas, imagens, depoimentos), que dizem respeito à relação do rio com a cidade. A pesquisa mostrou-me ser a investigação sobre a memória do rio um ponto de interesse para tocar o real da memória da cidade, buscando em especial os elementos significantes de um processo de urbanização, em sua relação com o chamado meio ambiente, e o modo como nele os sujeitos se produzem (urbanos). O recorte das análises aponta um caminho teórico-analítico que se delineia no sentido de compreender relações de atravessamentos entre nomeações e imagens.

Palavras-chave: memória discursiva; discurso ambiental; sujeito urbano; circulação do arquivo.

Introdução: o arquivo urbano e suas materialidades

Este é um trabalho que dá continuidade a análises anteriores (cf. SILVA 2011 e SILVA 2010), em um percurso que procurarei explicitar brevemente. Como docente da UNIVAS - Universidade do Vale do Sapucaí, localizada em Pouso Alegre, no Sul de Minas, voltamo-nos para elementos da memória local, em um projeto de pesquisa coordenado pela profa. Eni Orlandi. ${ }^{2}$ Dado o meu interesse em relação ao discurso ambiental, com o qual tenho trabalhado, descobri meu objeto no rio Mandu, em sua significação no âmbito do desenvolvimento da região, em especial da cidade de Pouso Alegre.

1 Doutora, docente do PPG em Ciências da Linguagem da UNIVÁS - Universidade do Vale do Sapucaí/ MG.

2 Trata-se do projeto "Discurso, individuação do sujeito e processos identitários - espaço, acontecimento e memória no Sul Mineiro" desenvolvido na Universidade do Vale do Sapucaí a partir de 2008. Alguns resultados desta pesquisa estão publicados em ORLANDI, E. (org.) Discurso, espaço, memória: caminhos da identidade no Sul de Minas. Campinas: RG. Editora, 2011. 
A pesquisa por mim empreendida, inicialmente no projeto citado, pautou-se em uma "leitura de arquivo" (Pêcheux 1992) sobre a fundação e o crescimento de uma cidade às margens do rio Mandu, no embate de diferentes memórias discursivas. Foi tratado, em um segundo momento, da constituição de um acervo fotográfico específico sobre o rio, como parte do arquivo histórico da/na cidade. E, dada a relevância que se mostrou nessa perspectiva de reflexão - ao abordar a memória de um rio, em uma determinada cidade -, a pesquisa, em um terceiro momento, dirigiu-se para um rio na cidade de São Paulo, isto é, para a compreensão da significação do meio ambiente como parte da memória urbana, a partir do Rio Pinheiros.

Assim, apoderando-me do fato de que muitas cidades brasileiras ergueram-se em locais ladeados e/ou cortados por rios - como São Paulo, que tem início com o colégio jesuíta construído entre o Anhangabaú e o Tamanduateí, ou Pouso Alegre, que começa com uma capela às margens do Rio Mandu -, a pesquisa mostrou-me ser a investigação sobre a memória do rio um ponto de interesse para tocar o real da memória da cidade, compreendendo em especial elementos significantes de um processo de urbanização, em sua relação com o chamado meio ambiente, e o modo como nele os sujeitos se produzem (urbanos, caipiras etc.).

Trata-se de refletir acerca do meio ambiente como elemento presente no (presentificado pelo) urbano, meio ambiente que aqui, neste estudo, figura através do rio (um dado rio), como parte de uma determinada cidade. Os gestos de nomeação (topônimos, legendagem...), como veremos, mostram o rio, sua significação sobredeterminada pelos discursos urbanos que se propagam: língua indígena e discurso religioso (capelas, nomes de santos associados/ contrapostos a nomes indígenas...), discurso urbanista (enchentes, pontes, obras públicas...), discurso ambiental (poluição) etc.

Conforme formulação de Pêcheux, "a memória discursiva seria aquilo que, face a um texto que surge como acontecimento a ler, vem estabelecer os 'implícitos' (quer dizer, mais tecnicamente, os pré-construídos, discursos-transversos etc.) de que sua leitura necessita: a condição do legível em relação ao próprio legível" (idem, p. 52).

Na concepção da análise de discurso, em seu dispositivo teórico-metodológico, mostra-se a não-homogeneidade e a não-coincidência no que diz respeito à memória que produz e é produzida por uma determinada sociedade. Mesmo em seus efeitos no arquivo, através da institucionalização da memória social, verifica-se, pela abordagem discursiva, versões ${ }^{3}$ divergentes, confrontos de uma voz outra para com o dizer "oficial". Ou seja, nas circulações do arquivo, contrapondo-se as diferentes formulações, encontramos, pelo discurso, as marcas do político (divisão de sentidos).

Pêcheux aponta para alguns dos desdobramentos da memória enquanto produção social e histórica, ao mencionar os “... sentidos entrecruzados da memória mítica, da memória social inscrita em práticas, e da memória construída do historiador” (1999, p. 50). Neste trabalho, tomamos também fotografias de acervos públicos e depoimentos (história oral), elementos que apontam para o estabelecimento de determinadas práticas sociais enquanto práticas de "documentação". Assim, conjuntos numerosos de imagens são traduzidos por nomeações que os organizam como significativas de uma dada obra (Construção da Perimetral; Retificação do rio Pinheiros), outros tantos conjuntos organizam imagens de enchentes etc.

É importante mencionar que o corpus desta pesquisa foi construído em etapas, através de uma sequência de análises em que tomamos primeiramente as narrativas de origem da

3 Conferir Orlandi (2004) quanto a uma compreensão discursiva para “versões". 
cidade de Pouso Alegre, depois as fotografias do rio Mandu no museu da cidade e finalmente fotos e depoimentos sobre o rio Pinheiros em São Paulo. Nas narrativas de origem, as diferentes versões apontam a não-coincidência (o político, pela divisão), mas também um "tecer sobre a ausência" (o não saber), que possibilita à história o seu atravessamento por discursos míticos e neles o imaginário de uma "terra desbravada", dos "pioneiros" etc.

Em relação especificamente aos acervos fotográficos, a partir de uma primeira abordagem (Museu Tuany Toledo, em Pouso Alegre), procurei refletir sobre a constituição dessa prática social, indagando especificamente acerca do modo de estruturação do acervo fotográfico sobre o (um) rio.

No decorrer do último século, a fotografia vem se introduzir na sociedade como possibilidade de acesso à história, à memória. Barthes (1984) fala de uma "força constativa" da fotografia que incide não sobre o objeto, mas sobre o tempo: a fotografia tem um "poder de autenticação", funciona como um "certificado de presença". Tendo em vista esse gesto de captura de um instante, no modo próprio de significar da fotografia, pode-se compreender seu funcionamento enfatizado enquanto "documento".

A partir da análise de discurso, pois, também a imagem é concebida em sua opacidade. A investigação de acervos fotográficos sobre o rio faz ver um rio pelo acontecimento do/ no urbano, um rio que se articula na significação das cidades. Não seria o rio, nesse contexto, o objeto da fotografia, mas um instante da cidade. Isto diz da fotografia como linguagem: a fotografia se faz como um gesto que captura e fixa algo que é um "instante de" (daí o termo instantâneo para designar também a fotografia).

O acervo pode integrar imagens advindas de álbuns de "fotos diversas" sobre a cidade ou de um conjunto mais específico, em que os sentidos de documento ficam mais evidenciados. Para exemplificar: 1) uma série de fotos sobre o rio Mandu, em Pouso Alegre, é nomeada "Construção da Perimetral", quando um braço do rio Mandu é aterrado; 2) uma série de fotos do rio Pinheiros em São Paulo é nomeada "Retificação do Rio Pinheiros", quando o curso do rio é alterado. Nesse âmbito, a fotografia se faz como gesto de documentação, sendo a imagem interpretada já de antemão como parte de um arquivo público urbano.

Sobre o corpus das imagens fotográficas, esta pesquisa se realizou com fotos do Rio Mandu, em Pouso Alegre, e do Rio Pinheiros em São Paulo. As fotos de Pouso Alegre estão no Museu Tuany Toledo, digitalizadas, mas não disponibilizadas on line.

Em um dado momento, a digitalização oferece a possibilidade da disponibilização/ circulação de documentos e imagens fotográficas pela rede. A contraposição de versões sobre a origem de Pouso Alegre em obras impressas (historiografia) e na rede deixa a ver de que modo a questão do arquivo é atravessada pela questão tecnológica, e suas implicações enquanto modos de formulação do (sobre o) arquivo - em que se observa a organização e reorganização, sustentada em/por deslocamentos discursivos.

Dois arquivos organizados on line sobre o Pinheiros estão entre os arquivos consultados: o arquivo da Fundação Energia e Saneamento, o qual disponibiliza, entre o seu material, os arquivos da Light, que incluem muitas imagens urbanas do início do século XX, pois a empresa foi responsável pela eletrificação de São Paulo; e o arquivo do Esporte Clube Pinheiros, que foi um clube de regatas, construído à margem do rio.

O livro O Rio Pinheiros, da Secretaria de Meio Ambiente de São Paulo, publicado em 2002, é comemorativo do início de um projeto do governo estadual que pretendia realizar a limpeza do Rio Pinheiros. O livro expõe depoimentos de moradores antigos do bairro de Pinheiros, obtidos através de projetos mais recentes de "memória oral". A prática da documentação pela memória oral, através da produção de depoimentos de diferentes sujeitos, 


\section{Conexão Letras}

oferece acesso às “outras vozes", em relação aos sentidos oficiais que se institucionalizam a partir de uma voz do governo ou de uma dada política. Procurei ouvir sentidos outros para as obras no rio Pinheiros que, na década de 1940, transformaram o bairro, através de uma análise do depoimento de um (ex) barqueiro, sujeito que se coloca, como veremos, no embate com a "versão oficial dos fatos". A análise desenvolvida sobre o Mandu, por sua vez, mostrou que a divisão entre as formações discursivas pode se inscrever no próprio "documento oficial". Retomarei brevemente a análise de dois recortes sobre as narrativas históricas da cidade de Pouso Alegre (publicadas em Silva 2010 e Silva 2011), momento em que percebi a possibilidade de explorar metodologicamente a questão das nomeações e regularidades discursivas sobre a relação do rio com a cidade.

Com o material tomado nessas análises, procurei compreender diferentes movimentos discursivos em que são produzidos sentidos para a relação dos sujeitos com o ambiente, relação que é histórica e ideológica. Em seu conjunto, as análises empreendidas se debruçam sobre nomeações de cidades e/ou nas cidades, imagens fotográficas, legendas, depoimentos... De modo amplo, o recorte das análises aponta um caminho teórico-analítico que se delineia no sentido de compreender relações de atravessamentos entre nomeações e imagens.

Na memória da cidade de Pouso Alegre, o nome Mandu, nome do rio em torno do qual a cidade cresceu, aparece como modo de identificação da própria cidade. Na importância do rio como parte dos processos de identificação do pouso-alegrense, percebe-se a ligação afetiva para com a cidade presente através deste que é um elemento constitutivo do que se convencionou chamar "meio ambiente".

Na memória da cidade de São Paulo, o Rio Pinheiros, como os demais rios paulistanos, também tinha um nome na língua indígena, chamava-se Jurubatuba. Pinheiros era o nome da aldeia, do núcleo caipira que se instalou à margem direita do rio, na mesma época da fundação de São Paulo (1560). Ou seja, nesse caso, ocorre o contrário do que ocorreu em Pouso Alegre, e o rio, em algum momento, passa a ser nomeado pelo nome do povoamento que o vive.

Observa-se que, em ambos os casos, as nomeações apontam para a presença indígena, embora nas narrativas de origem de Pouso Alegre não se faça menção a tribos indígenas, ao contrário do que ocorre nas narrativas de origem de São Paulo, em que o indígena está presente através da afirmação do estabelecimento do Colégio de São Paulo, voltado à catequese dos índios pelos padres jesuítas. O colégio é o marco da fundação da cidade, núcleo a partir do qual a cidade viria crescer e significar seus arredores, como o próprio bairro de Pinheiros.

\section{Duas versões: diferentes sujeitos na história, marcas no arquivo}

Nas narrativas de origem de Pouso Alegre, a cidade teria nascido com a construção de uma capela às suas margens, e o local foi inicialmente conhecido como Arraial do Bom Jesus de Matozinhos do Mandu. As análises realizadas sobre a nomeação de Pouso Alegre, a partir do rio Mandu mostram: os efeitos de sentido diferentes sobre a história de Pouso Alegre nas diferentes circulações (obra impressa e internet) e o confronto entre formações discursivas marcado na diferença de nomeação para a cidade (Pouso Alegre e Mandu). Essas análises são brevemente retomadas a seguir para que possamos compreender elementos específicos agindo na questão do arquivo.

Arraial do Bom Jesus de Matozinhos do Mandu: Nota-se que o nome do rio marca a localização do povoamento, especificando-o, pois o nome de um santo não será suficiente para dizer de uma determinada localidade. (Quantas Santanas, por exemplo, nós temos?) Em nossa história de colonização portuguesa católica, o nome do rio, ou de outro elemento 
do ambiente, passa a integrar o nome da localidade nomeada com o nome de um santo, funcionado como elemento que especifica, discrimina no contexto de um dado território.

Mandu constitui-se ainda hoje como uma referência importante para o pouso-alegrense, dado que é um nome presente em diversos estabelecimentos da cidade, como, por exemplo, no estádio, conhecido como "Manduzão". Sobre o funcionamento de um elemento enquanto "referência", observa-se que não se trata de uma relação que se estabelece a partir de um suporte no "concreto", mas que é elemento de memória, que se produz como efeito da inscrição do sujeito no simbólico. O material pesquisado (nomeações de um núcleo urbano) mostra os deslocamentos: dos nomes de santos portugueses para o Brasil, do nome no rio (do peixe) para o nome da cidade e em seguida para o nome de estabelecimentos $\mathrm{da} /$ na cidade...

Assim, a história da origem da cidade de Pouso Alegre liga-se ao meio ambiente pela sua nomeação, através da memória em torno do rio. Trechos de Pouso Alegre - origem da cidade e história da sua imprensa, de Amadeu de Queiroz, de 1948, são encontrados na internet. Em Silva (2010), analiso trecho da internet e sua relação com a obra impressa de Queiróz. O trecho analisado procura explicar a origem do nome "Mandu", apresentando as duas versões que circulariam a esse respeito:

Segundo alguns autores, o batismo da localidade como Mandu se derivou da corruptela do nome de um pescador ou tropeiro, que se chamaria Manuel atendendo pela alcunha de Manduca ou simplesmente Mandu, e que teria sido o primeiro povoador da região. Segundo outros, do tupi-guarani mandi-yu (mandi $=$ peixe e yu = amarelo). Atestam Marques de Oliveira e Augusto Vasconcelos que até 1799 a florescente povoação localizada às margens do Mandu era também conhecida pelo nome desse rio. (http://citybrazil.uol.com.br/mg/pousoalegre/historia-da-cidade).

Conforme apontei anteriormente (Silva 2010), em Amadeu de Queiroz também encontramos as duas versões, para explicar o nome Mandu como no trecho transcrito. Amadeu menciona a existência de uma versão que diz que o nome "Mandu" teria derivado do nome de um português chamado Manoel, de apelido Manduca, mas é por ele desacreditada. Para Amadeu de Queiroz (1948, p. 13-15), o nome Mandu, rio, derivou do nome Mandu, peixe, do tupi-guarani, mandi ou mandu, conforme se compreenda a pronúncia de uma vogal na língua tupi, que quer dizer "água", "rio". Tal explicação é apresentada por esse autor como a mais correta ou provável, dada a constância na forma "mandu" encontrada em documentos antigos e a pronúncia do fonema tupi em questão. Isto é, o texto de Amadeu menciona um deslocamento que teria ocorrido de mandi ("peixe", em tupi) para mandu, em função da sonoridade dessa vogal na língua tupi.

$\mathrm{Na}$ formulação encontrada em circulação na internet, as duas versões sobre a origem do nome "Mandu" se colocam como "diferença entre autores", nivelando o que se apresentaria na obra impressa como tendo estatuto distinto: uma versão remetendo à etimologia do tupi, considerando a não-correspondência fonética entre o português e o tupi, e a outra pautada em um personagem insólito, soando anedótica sobre a presença portuguesa. Além disso, apresenta-se de maneira mais positiva uma explicação etimológica outra: afirma-se uma contração de mandi (peixe) e $y u$ (amarelo).

Assim, no caso analisado, há diferenças em relação ao modo como se produz a função autor (Orlandi, 1988) em uma e outra circulação, diferenças que conduz a consequências quanto à memória histórica. O modo de formulação que encontramos na internet implica determinada discursivização da história, que tem como efeito despolitizar o acontecimento 


\section{Conexão Letras}

das línguas diferentes no território brasileiro: o fato de que as vocábulos possam ser falados de maneiras diferentes (não há correspondência entre os fonemas), pois, não se apresenta.

Na história de Pouso Alegre, como em outros locais no Brasil, verificamos que em determinados eventos a memória da língua indígena se expõe, como inscrição da materialidade da língua tupi na língua falada no Brasil.

O exemplo analisado contrasta duas diferentes formulações, que mantêm, ambas, a referência a duas versões sobre a origem da cidade. Em seu modo próprio de inscrição, em um e outro documento, essas diferentes versões constituem efeitos de sentido diversos sendo que o texto encontrado on line parece produzir certo "aplainamento" para os sentidos das relações entre língua tupi e língua portuguesa no Brasil. Na formulação da internet, as diferentes versões são remetidas, como já foi dito, a uma diferença entre autores, o que pode ser um elemento interessante para analisarmos. Na direção de compreender a história de um nome (Mandu/Pouso Alegre), mostra-se uma "disputa" entre duas versões, que, nos termos da $\mathrm{AD}$, podemos perceber como o lugar do equívoco na história. Na circulação de diferentes versões, apresenta-se o real da história, enquanto embate de sentidos.

As retomadas das obras dos historiógrafos locais, presentes hoje na internet, são significativas quanto à compreensão da memória discursiva, e as contradições e deslocamentos são marcas da divisão de sentidos que aí também se inscreve.

Da obra de Queiroz (1948) à rede, fica marcada a circulação de uma versão outra sobre o nome Mandu, expondo-se essa não-coincidência que caracteriza a memória discursiva. A versão de um português chamado Manuel de apelido Manduca, pescador ou tropeiro, soa anedótica (mítica?), mas aponta justamente para o imaginário de um povoamento brasileiro que se originaria da presença do português, e sua relação histórica com a região, que o significa pelo seu assentamento. Assim, nessa versão sobre a origem do nome Mandu a presença do índio é silenciada: Mandu não é um nome indígena, mas de um português chamado Manuel. De fato, esse silenciamento mostra-se na historiografia da região, que não faz referência aos povos indígenas em suas narrativas históricas.

\section{Duas nomeações: sobre os lugares do qual se fala}

Ainda quanto às análises realizadas (Silva, 2010) sobre as narrativas de origem de Pouso Alegre, foi muito significativo perceber certa repetição levada à circulação pela rede, proveniente de um enunciado pertencente a um documento histórico da cidade, documento que, ainda na época do Brasil Colônia, eleva à freguesia a categoria do núcleo urbano (de povoamento para freguesia). No documento de 27 de outubro de 1810, a "Mesa de Consciência e Ordens erige em Freguesia a Capella do Bom Jesus de Pouso Alegre do Bispado de São Paulo". No documento, encontramos o enunciado: "erigindo nova Freguesia na Capella do Bom Jesus de Pouso Alegre, vulgarmente do Mandu”. Em circulação na internet, as seguintes formulações:

Oito anos depois de inaugurada a capela, foi o povoado elevado à categoria de freguesia colada a do Senhor Bom Jesus de Pouso Alegre, vulgarmente chamada Mandu. ou

Criada a freguesia do Senhor Bom Jesus de Pouso Alegre, na capela vulgarmente chamada Mandu.

Cf. http://citybrazil.uol.com.br/mg/pousoalegre/historia-da-cidade; http://biblioteca.ibge.gov.br/visualizacao/dtbs/minasgerais/pousoalegre.pdf e http://www.acadpousoalegrensedeletras.com.br/ProsaII3arquivos/Parte1.EmProsaeVersoII.pdf. 
Em negrito, percebe-se que se mantém, do documento oficial, o gesto de renomeação, isto é, a menção a um nome ligado à capela, nome que é integrado na locução que associa o santo com a localidade (Bom Jesus de Pouso Alegre). Mas junto ao nome Pouso Alegre, integrado na locução, retoma-se o nome outro, o nome "vulgar", que é Mandu.

Sobre o enunciado do documento, é importante lembrar: como nele ficam identificados Pouso Alegre e Mandu como dois nomes de uma mesma localidade; como este documento é significativo de um momento em que a instância religiosa e a instância administrativa não se distinguem; como na estrutura sintática fica marcada a divisão política, entre o governo (o português) e o habitante local (o brasileiro).

$\mathrm{O}$ documento diz respeito a um contexto histórico em que vigora uma determinada associação entre o poder eclesiástico e o poder da coroa, na colônia: nota-se a referência ao bispado de São Paulo e a própria articulação sintática "nova Freguesia na Capella".

Marca-se na materialidade desse documento o "nome oficial" como Pouso Alegre, mas ao fazê-lo / para fazê-lo é necessária a referência ao nome Mandu. Ou seja, dizer Pouso Alegre pode não ser suficiente, necessita-se de Mandu, nome para o qual "há memória". Mas, na discrepância entre duas nomeações, o documento, enunciado do lugar do governo português, mostra um outro em relação ao governo, que é o habitante local, o brasileiro. Assim, conforme já afirmei em Silva (2010), "Pouso Alegre" e "Mandu" podem ser consideradas duas expressões diferentes que dizem a mesma região - remetendo a diferentes formações discursivas (Pêcheux, 1975), a região dita do lugar de um governo (Igreja/ Coroa) é Capela do Bom Jesus de Pouso Alegre e do lugar do habitante local é Capela do Mandu.

Através dessa dupla designação, no modo como ela se apresenta, o documento que produziu uma mudança de status de um dado povoamento no sul de Minas expõe uma divisão política. A esse respeito, pois, o interessante é essa retomada hoje por espaços e sujeitos que colocam na rede versões de um enunciado histórico, enunciado-marco da cidade de Pouso Alegre, que, em que se mantém determinados elementos sobre a formulação primeira: mantém-se a articulação entre Pouso Alegre e Mandu, a referência ao Bom Jesus, e o advérbio vulgarmente.

$\mathrm{O}$ enunciado mencionado traz as marcas da divisão política entre a posição do habitante local e a posição do governo (português). E é também significativo de um processo de nomeação que se dá no Brasil, a partir das sucessivas conquistas territoriais do governo português sobre uma terra "sem dono e sem lei" (Deus/ Estado). Da mesma forma, o nome da cidade de São Paulo origina-se na expressão São Paulo de Piratininga, expressão que inclui o nome do Planalto que se situa posteriormente à Serra do Mar, no qual foi erguido um colégio Jesuíta, para a catequese dos índios, entre os rios Anhangabaú e Tamanduateí.

\section{Acervos fotográficos: entre imagens e suas legendas}

Em um segundo momento, nessa pesquisa que abordou a memória, a partir da referência do rio Mandu, busquei o arquivo fotográfico presente no museu da cidade.

O Museu Tuany Toledo em Pouso Alegre possui, atualmente, um arquivo digitalizado de fotos do Rio Mandu, que foi construído pela organização de:

a) fotos esparsas que se situam em álbuns sobre a cidade em geral e

b) um arquivo nomeado "Construção da Perimetral", que documenta o momento em que um braço do Rio Mandu é aterrado na década de 80 dando origem à Avenida Perimetral. 
Assim, o material pesquisado pode ser compreendido através dessa divisão geral. De um lado, um conjunto nomeado, determinado pela lógica da administração pública, que toca o rio: construção de pontes, enchentes... De outro lado, fotos esparsas de um cotidiano urbano, em que o rio é apenas um dos elementos sendo flagrados. A essa divisão geral do material de arquivo sobre o rio podemos associar uma tensão entre os gestos de interpretação ligados às instituições, que produzem uma administração da memória, e outros gestos, aproximando estes últimos do que chamou Orlandi (2004) de "falas desorganizadas".

Quando parti para uma pesquisa sobre as imagens do Rio Pinheiros, em São Paulo, observei que havia uma regularidade, quanto a esses dois diferentes arquivos fotográficos, do Mandu e do Pinheiros, que são as fotos de enchentes e as fotos de obras públicas. Assim, um primeiro olhar sobre acervos fotográficos de diferentes cidades aponta para o fato de que o rio entra como elemento de um discurso fotográfico sobre a cidade a partir do acontecimento das enchentes e de inúmeras intervenções urbanas, realizadas em virtude de seu curso (como as pontes), ou que incidem em seu curso, como obras de contenção, construção de usinas e de barragens para a geração de energia, enfim...

Além dessa regularidade, pela inscrição das imagens do rio entre outras imagens (flagrantes) de uma dada cidade, observa-se, sobretudo a partir do conjunto diverso de fotos esparsas, uma relação de pertencimento: o rio pertence à cidade, dela faz parte e, nesse sentido, ele não é focado, ele mesmo, pelo fotógrafo da cidade, a não ser dado um acontecimento no cotidiano urbano.

Não se fotografa o rio, mas o cotidiano da cidade. As próprias legendas que acompanham as fotos são índices de que o objeto das fotos não é o rio: "Enchente de 1929", "Construção da Perimetral" etc. O que se fotografa, nesse sentido, é algo que ocorre, um acontecimento, como parte do cotidiano e da história de uma determinada cidade. Afora os arquivos de obras públicas, a visão da enchente, um evento ocasional no cotidiano da cidade/rio, "toma conta" do arquivo sobre o rio. A ocorrência abundante das fotos de enchentes e de obras é ainda reafirmada pela legendagem: por exemplo, "enchente de 1929" nomeia uma diversidade de imagens (fotos de prédios, pessoas, animais, mostrando-se aspectos muito diferentes), sendo encontrada tanto no arquivo do Rio Mandu, quanto no arquivo do Rio Pinheiros.

Sobre as obras públicas, nos dois arquivos mencionados, sobre o Rio Mandu e sobre o Rio Pinheiros, temos um conjunto de fotos nomeando uma grande obra: Construção da Perimetral e Retificação do Rio Pinheiros.

Tenho como objetivo compreender o modo como o rio - como figuração do meio ambiente - se faz presente nos acervos históricos urbanos, fazendo presentes determinados sujeitos/ práticas/ discursos. Segundo Orlandi, "Toda denominação acarreta um silêncio que o fato mesmo de nomear produz (1989)." Construção da Perimetral e Retificação do Rio Pinheiros são arquivos fotográficos cujas nomeações especificam intervenções sobre o corpo da cidade que envolvem o rio. Tais arquivos, assim significados, produzem uma voz oficial sobre a memória da cidade. Essa voz oficial mostra-se tomada pela evidência prática de uma construção da cidade, no âmbito da administração pública, que necessita das pontes, das grandes avenidas, da eletricidade em abundância...

Os arquivos fotográficos em suas nomeações exemplificam um gesto de leitura que, certamente, impõe-se sobre outras leituras do que estariam representando as próprias obras para o cotidiano da cidade: a construção de pontes ou outras obras e as enchentes. Por exemplo, as imagens do acervo da Fundação Energia e Saneamento possuem uma legenda que procura assegurar um tratamento técnico para esse tipo de material que se compreende, institucionalmente, como documentação fotográfica. O texto das legendas assume um caráter descritivo, e procura precisar, por exemplo, o local fotografado na cidade/rio: 


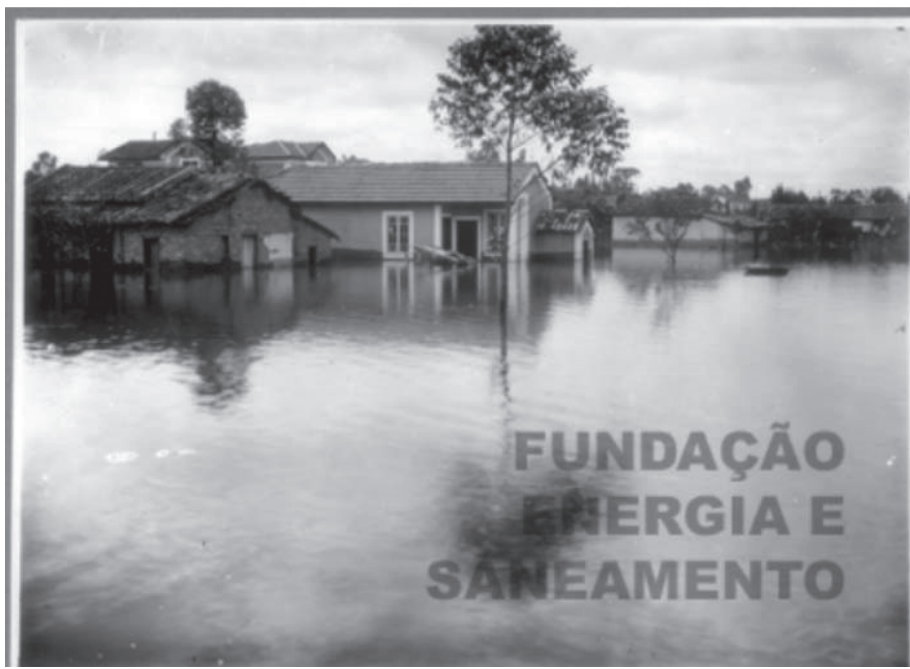

Legenda: Residências ao longo do rio Pinheiros na secção imediatamente acima da Av. Cidade Jardim durante a inundação de 1929. 1929

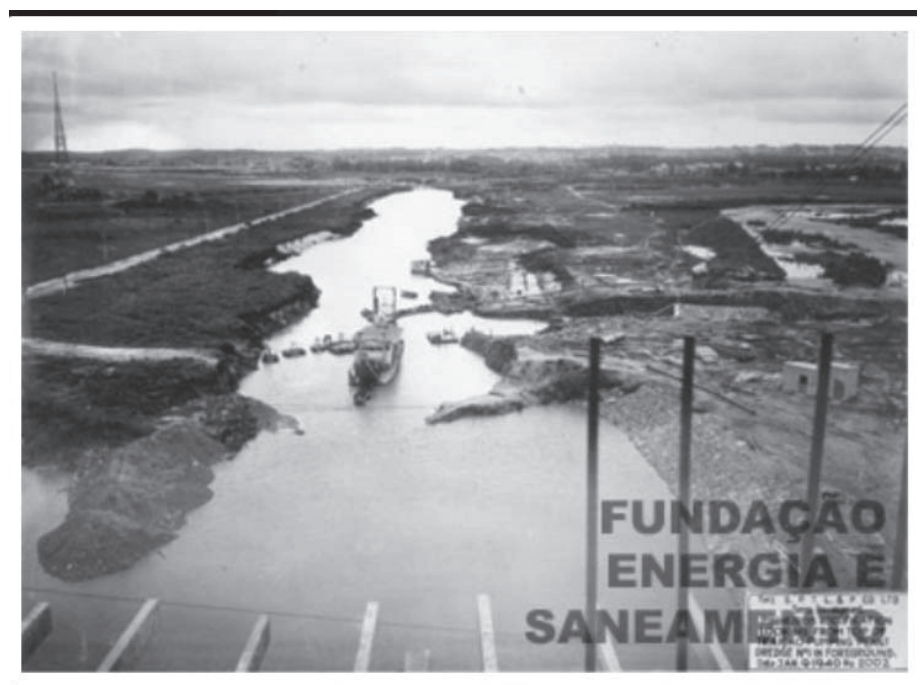

Legenda: Retificação do rio Pinheiros vista de cima da usina de bombeamento de Traição. Draga ${ }^{\circ} 1$ draga em primeiro plano. 1940

O rio é um elemento que, na construção das cidades, vai sendo inscrito simbolicamente em seu cotidiano pelos diferentes discursos e sujeitos urbanos: a navegação, as lavadeiras, os nadadores, as enchentes, as pontes, as obras públicas, o escoamento de dejetos... Ou seja, é um elemento significante desse cotidiano, como lazer, trabalho, acesso (transporte), obstáculo (ponte), enfim... No material pesquisado, encontramos algumas fotos que mostram: o habitante local, o trabalhador e o esportista do/no rio (a lavadeira, o barqueiro e o nadador). Tais imagens dialogam com a voz oficial sobre a história do rio, conforme a análise apresentada no próximo item. 


\section{A Retificação do Rio Pinheiros na memória do barqueiro}

As imagens fotográficas sobre o rio na cidade mostram uma sucessão cronológica em que primeiramente o rio era parte da cidade, parte de seu lazer e de seu trabalho, era parte da circulação dos sujeitos (lavadeiras, barqueiros, esportistas). O rio foi inicialmente local de trabalho (para o barqueiro de areia, por exemplo) e local de lazer (para os nadadores, para os atletas dos "clubes de regatas"). Depois, o crescimento das cidades "engoliu" o(s) rio(s), com a produção de energia elétrica, com o escoamento de dejetos etc. Ele foi aterrado, canalizado, coberto por avenidas, poluído... E o habitante das grandes cidades no Brasil, na maioria das vezes, não tem mais como se aproximar dos rios, às vezes grandes rios...

A seguir, realizo uma análise a partir de depoimento de um morador de Pinheiros, que foi trabalhador no rio, antes da obra chamada de "retificação". Através de sua voz, acompanhamos outra perspectiva sobre as mudanças no rio, no bairro e na cidade, sobre os sentidos que a obra pode assumir na memória urbana, fora do âmbito oficial de um governo da/na cidade, que planeja e acompanha suas obras.

O trecho apresentado a seguir é um material discursivamente muito rico. Nele, fala-se da imigração, das relações de trabalho nessa construção da cidade, fala-se de um ritmo de construção já intenso, nas décadas de 20 e 30 em São Paulo. Podemos dividir o trecho analisado em três partes: (1) apresenta-se o barqueiro dos barcos de areia no Rio Pinheiros; (2) o barqueiro presentifica em sua fala a lembrança dos diferentes trechos do rio (curvas, retas, corredeiras...), fazendo um percurso; (3) o barqueiro fala da obra realizada no rio.

\footnotetext{
Parte (1):

Vim pra trabalhar no rio, tirando areia, como grande parte do pessoal da minha terra. minha conta, mas descarregava pro patrão. (...) Tínhamos que tirar depressa a areia que ia construir São Paulo. (...)

Parte (2):

Cada curva tinha um nome: da ponte pra baixo, a da Cia. City, e depois uma reta até a Curva do $\mathrm{Cu}$. Em seguida uma reta funda até a Esquina do Caralho. Depois, a Curva dos Canos, da Ponte dos Canos.

Mas também as retas eram famosas: a Reta das Lavadeiras, a Reta do Alforrado, a Corredeira Pequena e a Corredeira Grande que ia dar na Reta dos Fios. Tudo tinha um nome porque quando nos encontrávamos um perguntava pro outro: você viu Fulano? Vi sim, em tal curva...

Parte (3):

$\mathrm{O}$ rio não foi mudado, foi endireitado. O leito continua o mesmo.

Trechos extraídos de O Rio Pinheiros.
} Era um serviço muito bruto que só português fazia. Eu era barqueiro. Trabalhava por

Na segunda parte, ao fazer a descrição do rio, observa-se um corte no fio do discurso, que se produz com a expressão "Mas também".

Através de uma marca na sintaxe, o falar do rio que conheceu fica dividido. Assim, esse segundo trecho divide-se em duas partes, pois, na nomeação dos trechos do rio, o Sr. Peralta fala muito significativamente primeiro das curvas, depois das retas. Marcam-se, nesse falar do rio, as instalações da cidade: a Curva da City, a Curva dos Canos e a Reta dos Fios. Fala-se aí da Cia. City, empresa que loteou a região hoje conhecida como Alto de Pinheiros, que tinha um porto de areia no rio. Fala-se dos Canos (da Ponte dos Canos) e dos Fios: um olhar do habitante sobre pontos da cidade em que ela deixa ver o modo como a energia e o abastecimento marcam a paisagem, "urbanizando o ambiente".

Ao lado das referências aos pontos em que são visualizados esses elementos da "urbanização" (canos, fios...), aparece outra forma de nomeação, esdrúxula, pela referência a 
partes íntimas do corpo. Nesse depoimento, o barqueiro fala como um sujeito que conheceu o rio intimamente, conheceu por dentro (dele); um sujeito que pode nomear cada trecho, demonstrando-se essa intimidade; um sujeito que, junto com outros, podia falar "o rio", localizando nele o paradeiro de seus companheiros: uma fala entre barqueiros. E o barqueiro fala muito significativamente primeiro das curvas - era nas curvas que o barqueiro trabalhava, retirando areia. A curva faz a areia se acumular.

A expressão "mas também" marca uma separação no fio do discurso. Então, Seu Peralta fala primeiro das curvas do rio, de um rio que era navegado antes de 1940, quando a obra chamada de "retificação" se realiza. As curvas se fazem presentes na sua fala, e ao final o barqueiro diz do rio que foi "endireitado", como fosse essa uma obra urbana moralmente necessária, e podemos talvez escutar os "nomes feios" com que se identificam as curvas como essa imoralidade, a qual se pôs um fim, "endireitando" o rio.

Vejo a produção desse corte no fio do discurso, quando o barqueiro está falando do rio, em uma relação para com a significação da obra urbana sobre o rio. A respeito dessa obra, ao fim, como quem aceita a designação da obra (retificação) ele diz: "O rio não foi mudado, foi endireitado. O leito continua o mesmo". Como quem aceita a retificação, ele não a diz diretamente, mas desliza para as paráfrases (de retificar para mudar e endireitar). No deslizamento, adentram outras questões: o que muda? o que continua?

Um corte: a obra também produziu um corte (antes/depois), desmanchando não só a identidade das curvas do Rio Pinheiros, mas também a das retas. Depois de 1940, o rio não tem mais as curvas, mas também não tem mais as retas, que também eram famosas. Nesse contexto, nesse conflito, o "mas também” vem significar de diversos modos.

Em relação à "retificação" - "mas também as retas eram famosas" -, o Sr. Peralta contrapõe-se à ideia de que o rio era só feito de curvas imorais. A intervenção sobre o rio pode ter tido para o barqueiro o sentido de uma ordem moral urbana em que se trabalha a cidade, a sua construção. Nesta, coube ao rio ser "enquadrado". E então no enunciado "O rio não foi mudado, foi endireitado", soa o enunciado oposto: o rio foi mudado, não endireitado.

$\mathrm{O}$ rio é mudado no processo de retificação, deixando de ser aquele rio que o Sr. Peralta conheceu. Mas também vem significar em relação à mudança que reconfigura não apenas um rio, mas uma região, uma população: Pinheiros era um bairro de lavadeiras e barqueiros, identidade que se perde na "modernização" da cidade. Depois de 1940, (o rio) Pinheiros não tem mais curvas, mas também não tem mais barqueiro retirando areia nas curvas; (o rio) Pinheiros não tem mais a Reta das Lavadeiras, mas também não tem mais moças lavadeiras lavando a roupa dos moços barqueiros...

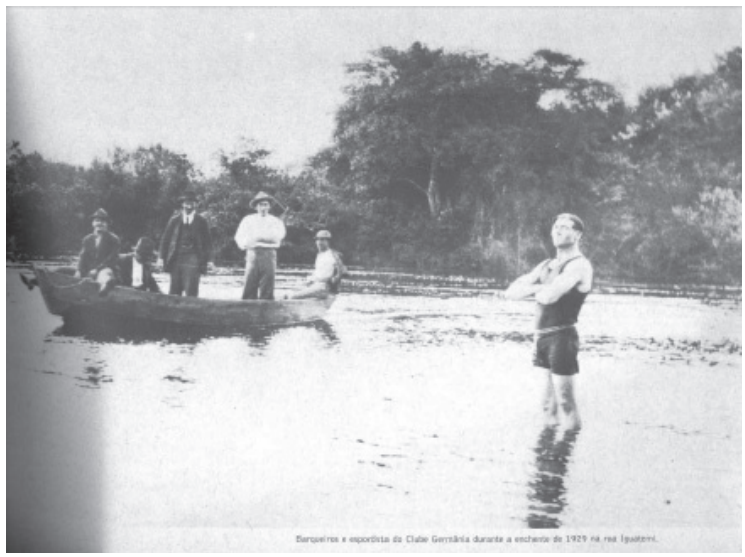

Centro Pró-Memoria Hans Nobiling do Esporte Clube Pinheiros 


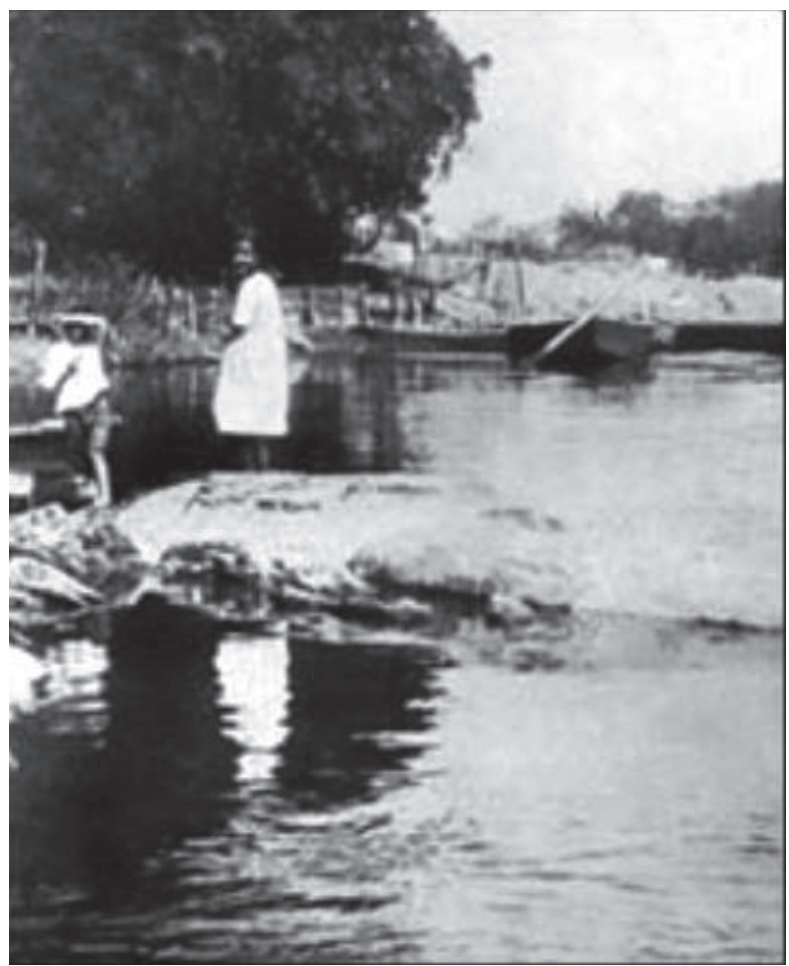

Centro Pró-Memoria Hans Nobiling do Esporte Clube Pinheiros

\section{Referências}

BARTHES, R. A câmara clara. Rio de Janeiro: Nova Fronteira, 1984.

CÂMARA MUNICIPAL DE POUSO ALEGRE, Museu Histórico Municipal Tuany Toledo, Pouso Alegre através dos tempos, s/d.

GOUVÊA, O. M. 2004. A história de Pouso Alegre. Pouso Alegre: Gráfica Amaral, $2^{\mathrm{a}}$. edição.

GOVERnO DO ESTAdo DE SÃO PAULO, Secretaria de Meio Ambiente, O Rio Pinheiros, 2002.

ORLANDI, E. "Silêncio e implícito (produzindo a monofonia)". In: GUIMARÃES, E. (org.) História e sentido na linguagem. Campinas: Pontes, 1989.

. Cidade dos sentidos. Campinas: Pontes, 2004.

. (org.) Discurso, espaço, memória: caminhos da identidade no Sul de Minas.

Campinas: RG Editores, 2011.

PÊCHEUX, M. "Papel da memória”. In: ACHARD, P. (et. al.) Papel da memória. Tradução e introdução José Horta Nunes. Campinas: Pontes, 1999.

. "Ler o arquivo hoje". In: ORLANDI, E. (org.). In: Gestos de leitura. Campinas:

Editora da Unicamp, 1992.

. (1975) Semântica e discurso: uma crítica à afirmação do óbvio. Tradução Eni

Orlandi et al. 2.ed. Campinas: Editora da Unicamp, 1995. 
SILVA, T. D. "Pouso Alegre do Mandu: meio ambiente e memória". In: Revista Entremeios: revista de estudos do discurso, vol. 1 n.1., 2010.

. "O Pouso Alegre do rio Mandu”. In: ORLANDI, E. P. (org.). Discurso, espaço, memória: caminhos da identidade no sul de Minas, p. 69-80, 2011.

QUEIRÓZ, A. Pouso Alegre: origem da cidade e a história de sua imprensa. Belo Horizonte: Imprensa Oficial, 1948. 